\title{
Effect of Impeller Position on Crystal Growth Kinetics of Borax in Dual Axial Impeller Batch Cooling Crystallizer
}

\author{
Antonija Čelan¹, Marija Ćosić1, Igor Pehnec ${ }^{2}$, Nenad Kuzmanić1 \\ ${ }^{1}$ University of Split, Faculty of Chemistry and Technology, Department of Chemical Engineering \\ R. Boškovića 35, 21000 Split, Croatia \\ akacunic@ktf-split.hr; akrap@ktf-split.hr; kuzmanic@ktf-split.hr \\ ${ }^{2}$ Faculty of Electrical Engineering, Mechanical Engineering and Naval Architecture, Department of Mechanical \\ Engineering and Naval Architecture \\ R. Boškovića 32, 21000 Split, Croatia \\ ipehnec@fesb.hr
}

\section{Extended Abstract}

To produce crystals of specified properties, it is of enormous importance to select the adequate mixing conditions in the crystallizer. When mixing is performed in a batch cooling crystallizer with a dual impeller configuration, this selection becomes even more complicated because the overall fluid flow pattern depends on speed, type, size and position of the impellers used. The overall fluid flow can potentially affect two main steps of the crystallization process; nucleation and crystal growth, both of which are decisive for the size distribution of the crystal product. Therefore, an impact of mixing parameters on nucleation and crystal growth kinetics in mixed crystallizer needs to be clarified [1].

In this work, an influence of spacing between two axial impellers, mounted on the same shaft, on crystal growth kinetics of borax in a batch cooling crystallizer was analysed. The crystallizer was a flat-bottomed vessel with diameter $T=0.24 \mathrm{~m}$, equipped with four baffles. The liquid height to vessel diameter ratio, $H / T$, equalled 1.3. In order to analyse the influence of the impeller spacing, $S$, on the crystal growth kinetics, experiments were carried out at different impeller $S / D$ ratios, ranging from 0 to 1.50 , while the lower impeller off-bottom clearance $(C / D=1)$ was kept constant. Mixing was performed by two four-blade $45^{\circ}$ pitched blade turbines (PBT) with diameter $D=0.3 T$, at just suspended impeller speed ( $\left.N=N_{\mathrm{JS}}\right)$. This speed was determined in preliminary examinations by a visual method $0.9 H$ proposed by Mersmann and Einenkel (1977) [2]. Unseeded batch cooling crystallization was carried out from a borax solution saturated at $30^{\circ} \mathrm{C}$ and cooled down at a constant cooling rate of $6{ }^{\circ} \mathrm{C} / \mathrm{h}$. Upon the onset of nucleation, which was detected by the turbidimetric method, samples of crystal suspension were withdrawn from the reactor in a defined process time in order to determine the size of the growing crystal by the laser scattering particle size distribution analyser Horiba LA-300. The simultaneous supersaturation change was determined from concentration which was measured in line by a sodium ion-selective electrode. In order to analyse energy requirements for mixing, torque was measured by Himmelstein MCRT-4800 torque transducer from which the power consumption per unit mass was calculated. To gain insight into the hydrodynamics of the crystallizer, computational fluid dynamic (CFD) simulations of fluid flow by Ansys Fluent 17.2 were made at examined conditions and the fluid flow pattern was analysed in detail.

Results based on experimentally determined crystal growth rates suggest that crystal growth was integration limited at all examined conditions, while values of the overall crystal growth rate significantly varied with $S / D$ ratio. This finally reflected on the properties of the crystal product as well. By taking into consideration the kinetic parameters of crystal growth, CFD simulations, crystal size distribution and power consumption it is possible to define the impact of the dual PBT impeller spacing on borax crystal growth kinetics.

\section{Acknowledgment}

This research was supported by the Croatian Science Foundation and is a funded by the HETMIX Project (IP-20138959). 


\section{References}

[1] A. Kaćunić, M. Akrap, N. Kuzmanić, "Effect of impeller position in a batch cooling crystallizer on the growth of borax decahydrate crystals," Chem. Eng. Res. Des. vol. 91 no. 2 pp. 274-285, 2013.

[2] W. D. Einenkel, A. Mersmann, "The Agitator Speed for Particle Suspension," Verfahrenstehnik, vol. 11 pp 90-94, 1977. 